\title{
Modernidade, Educação e História da Educação
}

Modernity, Education and History of Education

Modernidad, Educación e Historia de La Educación

Bruno Bernardes Carvalho

Instituto Federal de Educação Ciência e Tecnologia do Triângulo Mineiro (Brasil)

https://orcid.org/0000-0002-2451-3666

http://lattes.cnpq.br/1485505154398606

brunobernardes@iftm.edu.br

\section{DA CADEIRA}

AO ESCOLA E MODERNIZAÇÃo

$\mathrm{BANCO}$

\section{JUSTINO MAGALHÃES}

MAGAlHÃES, Justino. Da Cadeira ao Banco: Escola e Modernização (Séculos XVIII - XX). Lisboa: Educa; Unidade de I\&D de Ciências da Educação. 2010. 644p. 
A obra "Da Cadeira ao Banco: Escola e Modernização (Séculos XVIII - XX)", de autoria de Justino Magalhães, professor catedrático do Instituto de Educação da Universidade de Lisboa, é leitura essencial aos pesquisadores da História da Educação. Partindo da metáfora que dá título ao livro, o autor faz uma incursão pelos séculos XVIII ao XX, munido pela erudição que lhe é peculiar. Além do profundo trabalho de pesquisa, o autor nos oferece uma visão sobre a "história da longa duração", isto é, o processo histórico de constituição da escola e da educação escolar enquanto instituintes e institutos da Modernidade na Europa. Adotando a perspectiva da síntese historiográfica, pela visão ampliada do processo de escolarização, o conjunto de análises e reflexões apresentadas na obra são importantes contribuições à historiografia educacional, pois faz emergir categorias de análise, que servem de aporte para outras investigações, como por exemplo: estatalização; nacionalização; governamentação; regimentação; cultura escrita; e munícipio pedagógico, discutidas em artigos e livros anteriores por Justino Magalhães.

O livro divide-se em três partes: Questões Introdutórias; Parte I - História do Educacional Escolar Português; e Parte II - Da Cadeira ao Banco. A primeira é composta por ensaios que versam sobre a História da Educação, enquanto área de pesquisa, e a escola como objeto historiográfico. Magalhães (2010) ressalta o vínculo existente entre história e educação, e entre educação e sociedade. Coloca em relevo a educação e o educacional escolar como elementos basilares da Modernidade, aqui entendida como o longo ciclo histórico que abrange os séculos XVIII a XX. Também destaca que a escola e a cultura escolar, no desenvolvimento histórico, tornaram-se constitutivas e instituintes da Modernidade, desempenhando papel de relevo na modernização da sociedade e no processo de constituição dos estados nacionais. Nesse âmbito, a educação, e mais especificamente a educação escolar, mediante a generalização da cultura escrita, forneceu as bases de legitimação para constituição e afirmação do Estado em relação à sociedade. Pensada e institucionalizada como forma de regenerar a sociedade via consecução da cidadania, a escola evoluiu assentada no paradoxo modernização-tradição, de preparar o futuro pela reafirmação do passado. Questões que ele procura demonstrar tomando por mote a análise do caso português, objeto do capítulo seguinte. Além deste argumento central, o tópico introdutório contém reflexões sobre a História, a prática historiográfica e a pesquisa em História da Educação, sendo que o autor defende uma perspectiva epistemológica que perpasse diferentes dimensões espaço-temporais: curta, média e longa duração; local, regional e nacional; em escalas micro, meso e macro.

Já na Parte I, História do Educacional Escolar Português, Magalhães procura "reconstituir" a gênese e desenvolvimento da escola em Portugal, buscando estabelecer a cronologia desenvolvimento do sistema educativo português, tomando sempre em consideração o educacional escolar, como resultante da relação escola-sociedade. O período analisado (séculos XVIII - XX) é caracterizado por ciclos: estatalização, nacionalização, governamentação e regimentação. Progressivos e integrativos, cumulativa e lentamente resultaram na institucionalização da escola em Portugal, numa perspectiva da História enquanto processo.

A estatalização compreende o período que vai de 1752 quando Marquês de Pombal assume o poder, até 1820, com a Revolução Liberal do Porto. Compreende, assim, o seguinte feixe de características e processos: a ênfase da escrita como elemento de estruturação e organização do social; a escolarização do ensino e da cultura escrita; a escrita e a escola enquanto condição e instância de civilidade, ou seja, a emergência de "um proto-sistema escolar", conforme nominado pelo autor, pois com esta estrutura "embrionária" se estabelece o "Subsídio Literário". Neste cenário a instrução adquiriu centralidade, tornando-se matéria de interesse público, desígnio a ser assumido pelo Estado. Iniciava-se a transfiguração da educação em tecnologia do social, como meio de racionalização da sociedade e do estado nacional.

A partir da implantação do liberalismo em Portugal (1820), o desenvolvimento histórico educacional português promove um processo de nacionalização, já que a ênfase 
passa a recair na consolidação da nacionalidade portuguesa. A instrução pública acena com centralidade na construção de uma identidade pátria, a escola e a cultura escolar são nacionalizadas, mediante alguns processos a se destacar: a nacionalização curricular; a burocratização da estrutura escolar; a normalização pedagógica; protagonismos das instâncias locais, em especial as paróquias e municípios; adoção e reforço da língua vernácula como base da cultura escrita e da cultura escolar. Escola e nacionalidade caminharam associadas no período em questão, valorizando-se o nacional, as tradições e os valores pátrios, visando a construção de uma portugalidade.

O terceiro período histórico do desenvolvimento educacional português, trabalhado por Magalhães, século XIX, é caracterizado como ciclo em que a educação escolar se estrutura num sentido de maior organização e burocratização. Para Magalhães a escola nacional, além de reconfigurar o sentido do escolar, instala a governamentação, ou a burocratização do educacional escolar, com vistas a modernizar a escola e, por conseguinte, transformar a sociedade. O Estado português assume maior protagonismo na organização da escola, instituindo normas de escrituração escolar, uniformizando o currículo, criando órgãos de governo para inspeção do ensino, ampliando o aparelho pedagógico-administrativo, profissionalizando o magistério, enfim, variadas ações no sentido de conferir uma racionalidade burocrática à educação. Organizando a escola, pretendia-se o ordenamento e a regeneração da sociedade.

Há que se destacar também neste ciclo de governamentação, o papel desempenhado pelos municípios na organização da instrução em Portugal. Muito embora as ações empreendidas pelo governo português indiquem uma centralidade, com o estado nacional promovendo a normatização do escolar, os municípios portugueses contavam com certa porção de autonomia, resultado da descentralização administrativa, constituindo-se como "municípios pedagógicos", espaços não somente de ação e decisão política, mas territórios essencialmente pedagógicos, educacionais, envolvendo-se diretamente na organização da instrução em seus domínios. É possível afirmar que exista uma autonomia regulada, ou seja, uma descentralização normatizada, em que as instâncias locais contavam com certo grau de autonomia, ao passo que o estado nacional, sobretudo, por meio da inspeção de ensino, normatizava e conferia uma racionalidade burocrática a educação escolar.

Por fim, o quarto ciclo histórico caracterizado pelo autor, a regimentação, define um período de vínculo e condicionamento entre escola e regime político. Trata-se de uma aproximação, ou mesmo de uma fusão entre os ideais do regime político instituído e a educação, entre a escola e o Estado. A escola é literalmente regimentalizada, ou nas palavras de Magalhães (2010), tem-se a "prevalência do Estado, arrastando e arrestando a escola para si" (p.349), uma aliança entre escola e regime com vista ao progresso do país. O período de regimentação abrange tanto a República quanto o Estado Novo em Portugal ${ }^{1}$. Durante o período republicano a tônica recai em republicanizar a escola, a fim de se republicanizar o país. Fundem-se neste sentido os ideais de cidadania, republicanismo, nacionalismo, patriotismo. A escola republicana objetivava formar o cidadão republicano, o homem novo. A escola emerge neste período consolidada enquanto tecnologia do social, como meio de ordenação e progresso da sociedade. Pela via da escolarização pretendia-se a regeneração do social. E no que se refere ao chamado Estado Novo em Portugal, tais concepções são ainda mais acentuadas durante a administração salazarista: reforça-se a ideologização do ensino, com forte apelo cíviconacionalista. Conforme metáfora do autor, "do velho se fez novo", o Estado Novo se apropria da regimentação do educacional republicana, reincidindo sobre o teor nacionalista.

Na Parte II da obra, "Da Cadeira ao Banco", o autor retoma os quatro ciclos históricos apresentados na seção anterior, agora tomando por argumento central a cultura escolar e seu

\footnotetext{
${ }^{1}$ A implantação da República em Portugal data de 1910, enquanto que o Estado Novo tem sua origem em 1926, perdurando até 1974, sendo também este último período denominado de salazarismo.
} 
processo histórico de constituição. Somente aí temos claramente apresentado o conceito presente na metáfora da "Da cadeira ao Banco": assim como a criança, que ao entrar na escola levava consigo sua própria cadeira, e ao passo de seu desenvolvimento intelectual ascendia à bancada e à mesa central, a escola enquanto instituição social, também pode ser entendida metaforizada num processo de crescimento, que perpassa segundo o autor, dois séculos de história. Nesta parte da obra a cronologia não é mais o ponto principal da análise, mas sim os aspectos gerais e mais profundos que caracterizam o desenvolvimento da escola em sua relação intrínseca com a sociedade. Magalhães destaca que: "O processo de passagem da cadeira ao banco/ bancada espelha a evolução da instituição escolar, no plano interno e na sua relação com a sociedade (...).”. (p.414)

Da cultura escolar em Portugal, instituída historicamente e instituinte do social, são indicados os vetores centrais do processo de constituição do escolar em Portugal: a universalização da escola e da cultura escrita ao longo destes dois séculos; a escola concebida como como tecnologia do social, via de legitimação e consolidação do Estado-Nação; o paradoxo escolar de construção do futuro pela preservação da tradição, ou em outras palavras, a contradição escolar de pretensamente fornecer os meios de regeneração e progresso da sociedade, mediante a reafirmação de valores pátrios e da tradição; o crescente processo de regulamentação e burocratização do educacional escolar, aliado as ideologias dos regimes políticos; o caráter essencialmente educacional da Modernidade, na estreita e complexa relação existente entre modernidade, cultura escrita, escola, cidadania e estado-nação. Em linhas gerais, esta segunda parte da obra cristaliza a concepção de que a cultura escrita como meio, e a escola como centro, caracterizam a Modernidade enquanto processo civilizacional, destacando a relevância e o significado histórico do processo de escolarização como instância de modernização da sociedade portuguesa.

Importante mencionar que o autor dedica um capítulo especial para análise da realidade educacional brasileira, demonstrando inclusive diálogo fértil com pesquisadores brasileiros. Empreendendo uma análise comparada, analisa os ciclos históricos do educacional no Brasil, tomando por base as mesmas categorias do caso português: estatalização, nacionalização, governamentação e regimentação. Dentre outras questões, Magalhães (2010) destaca o papel desempenhado pelos municípios na organização da instrução primária brasileira, apontando para uma municipalização da instrução.

Numa inapropriada síntese, dada a complexidade e profundidade da obra em tela, aos que se interessarem pela leitura e pelo vaivém "Da Cadeira ao Banco", será possível ter uma melhor compreensão da relação existente entre escola, sociedade e Modernidade. Enquanto tecnologia do social a escola é instituto e instituinte, fator de modernização. À imagem da criança que adentra à escola com sua cadeira, somos conduzidos pelo autor, que espelhando a ação do mestre nos insta à aprofundar nosso entendimento sobre o processo de escolarização, tomando nosso lugar na bancada ao centro da sala. 